\title{
Public health leadership education in North America
}

This article was published in the following Dove Press journal:

Journal of Healthcare Leadership

30 March 2010

Number of times this article has been viewed

\author{
Hideo Uno \\ Kenneth Zakariasen \\ Department of Public Health Sciences, \\ School of Public Health, University \\ of Alberta, Edmonton, AB, Canada
}

\begin{abstract}
Public health leadership is one of the priority disciplines public health professionals need to learn well if they are to deal with demanding public health issues effectively and efficiently. This article looks at the trends in public health leadership education by reviewing the literature and using the Internet to explore the public health leadership programs offered in various parts of the world, and suggests several principles to be taken into account for the development of public health leadership education in the future. A variety of educational programs in public health leadership are classified into several types in terms of their formats: degree programs offered by schools of public health or other programs of public health, those offered in partnership with public health agencies, and so on. All of these programs have important implications for the overall effectiveness of public health leadership education. For public health leadership education to be effective, the partnership between academia and public health agencies is vitally important. Programs should provide opportunities to learn on the basis of practical public health experience, a commitment to life-long learning, flexibility in design, and recognition of the diverse needs of individuals and communities. The application of distance learning methods is one of the options to make this possible.
\end{abstract}

Keywords: public health leadership, public health professionals, school of public health

\section{Introduction}

The number of public health threats occurring around the world, such as terrorism and pandemics, has increased the work of the public health workforce so that it is now more visible to the general public. At the same time, these threats have accentuated the need for trained public health professionals. The development of the public health workforce, especially the training of public health leaders, is one of the pressing issues in strengthening the public health systems of countries all over the world. Through review of the literature and programs offered through a variety of institutions, we will discuss how public health leadership education (mainly in North America) is currently offered, and provide some perspectives on how such training may be enhanced.

\section{The need for leadership in the public health arena}

Very recently, swine influenza has become a public health threat all over the world. The virus, thought to originate from Mexico, first spread within a short period of time around North America. The press reported information about the cases caused by this virus almost every day. Images in which many people with masks on their faces were walking in the streets of Mexico were seen on television news. Medical officers 
from such organizations as the Centre for Disease Control and Prevention (CDC) or the World Health Organization announced the seriousness of the situation on television. People throughout the world paid attention to this public health crisis. For these kinds of pubic health problems, the public health role is quite clear to the general public. The political aspects in the decision making process would seem comparatively small in these kinds of public health activities. However, the front line professionals in public health have to quickly and effectively tackle what human beings might never experience, not only to keep the infection from spreading and to reduce the casualties, but also to maintain stability in people's lives, taking economic impact on the entire society into account.

The public health professionals, including public health officers, take initiative at the front lines to deal with public health issues. As the public health issues we are facing have broadened and become more complicated to impact the whole world, such as the influenza pandemic, public health professionals have had more opportunities to experience a variety of challenges posed by our increasingly complex society. Are public health professionals such as nurses and physicians prepared to deal with such broad and difficult issues? Are they all experienced? Are they all qualified as leaders, both in public health content knowledge and in leadership skills? They may have learned a broad range of health disciplines in which new scientific knowledge is always expanding in academia. However, many are focused on clinical aspects such as diagnosis or treatment at the individual level, but they have little chance to learn about effective management and leadership to achieve the goals of overall health at the macro level, such as community, country, and world. As new medical school graduates, public health physicians are often tested by being placed in difficult positions without the sufficient experience, knowledge, and skill-sets required to be effective leaders and managers. Roemer et al suggest that there are eight requirements for effective leadership in public health: knowledge of public health issues and programs; basic education and experience; organizational and administrative support; training in management; practical experience in management; adequate physical resources; favorable moral or spiritual environment; and personality. ${ }^{1}$ We find it interesting that training and practical experience in management are included among the eight requirements, but leadership training and practical experience aren't even mentioned. Perhaps confusion between what management and leadership are really each about has led to the deficit in effective leadership that has affected so many sectors of our society. How can public health professionals learn about these eight factors, and about what effective leaders really do in practice?

\section{The trends in the public health arena}

Regardless of their professional backgrounds, public health professionals usually obtain knowledge and skills through their daily activities, that is, through on the job training. Numerous public health issues confront them every day. They usually deal with them over a long period of time such as a few months or a year or more. At other times, they are required to make urgent decision when pressing crises occur such as natural disaster, outbreak of infection, and so on. They never lack lessons in the front lines of public health.

On the other hand, post-secondary education, for example Master of Public Health (MPH) programs, are one of the popular options, offering opportunities to learn the public health discipline throughout the world, especially in the United States (US). However, even in the US there are not sufficient public health professionals who have some formal public health training such as graduate degree programs. ${ }^{2}$ There are several possible reasons for this. First, since there is no common credential requirement for all public health professionals like a medical license, many people have entered careers in public health even though they may have no health background, which does emphasize that public health is an interdisciplinary field. Before entering the public health arena, those who are not health professionals do tend to seek study at some degree program regarding public health, whereas health professionals such as nurses and physicians may directly enter the field of public health. Second, public health professionals are so busy that they have found it difficult to study as fulltime graduate students to earn an MPH because it takes at least one year to complete for full-time students. The lack of common credential requirement for all public health professionals also might be a disincentive to study public health in some degree programs unless the organizations for which they work give them the chance to continue their careers along with their studies. Finally, they may merely feel that there is no need or no attractive educational pathway to earn an academic degree. For some seasoned public health professionals, a master's degree may not necessarily impart the expected knowledge and skills to deal with the difficult tasks they face in real settings, and thus does not attract them. There appears to be some mismatch between the educational supply to, and the demand by, public health professionals relative to both curriculum content and teaching approaches. 
Since the 1990s, a number of public health organizations and academic institutions in the US have discussed and attempted to develop public health core competencies for public health professionals to create alignment that addresses this mismatch. ${ }^{3}$ The Council on Linkages Between Academia and Public Health Practice developed core competencies for public health professionals: analytic/assessment skills; policy development/program planning skills; communication skills; cultural competency skills; community dimensions of practice skills; public health sciences skills; financial planning and management skills; and leadership and systems thinking skills. ${ }^{4}$ The Association of Schools of Public Health (ASPH) endorsed the core competencies developed by the Council on Linkages and developed the core competencies for the graduates of an MPH. ${ }^{5}$ The ASPH presented seven interdisciplinary/cross-cutting competencies: communication and informatics; diversity and culture; leadership; professionalism; program planning; systems thinking; and public health biology. These supplement the conventionally accepted five competencies: biostatistics; epidemiology; environmental health science; health policy and management; and social and behavioral sciences. ${ }^{6}$ The Public Health Agency of Canada developed a report entitled "Core competencies for public health in Canada" in 2007. In this report, the core competencies were organized under seven categories: public health sciences; assessment and analysis; policy and program planning, implementation and evaluation; partnerships, collaboration and advocacy; diversity and inclusiveness; communication; and leadership. ${ }^{7}$ Both the competencies developed by the ASPH and by the Public Health Agency of Canada are designed for the graduate level public health professionals, and both reports have common aims which will serve as a guide for academic institutions that develop curriculum content of master's level programs. According to the Public Health Foundation report, 91 percent of schools and programs in the US applied the core competencies into their curricula. ${ }^{8}$ Such a competency based approach is found also in the United Kingdom (UK) and Australia.

\section{Public health leadership education outside Canada}

Along with the above mentioned trends of competency development regarding public health practice, competency in public health leadership was developed by the National Public Health Leadership Development Network in the US. ${ }^{9}$ In response to the Institute of Medicine's (IOM) report "The future of public health" published in 1988, the schools in the US have started trials of rebuilding the curricula in varied manners. ${ }^{10} \mathrm{~A}$ variety of graduate educational programs and other training programs in public health leadership are classified into several types in terms of the formats below.

First, the degree programs offered by schools of public health or programs of public health include certificate, master (MPH), doctor of public health (DrPH) and so on. Some degree programs focus on public health leadership, but others just offer courses on public health leadership, as one of the electives. Of forty schools of public health accredited by the Council on Education for Public Health (CEPH) (except two schools outside the US), seven schools of public health offer the degree programs on public health leadership (two certificate, three master, three doctor) and twenty five schools provide courses focused on public health leadership, as of June 2009. The executive master's program is also one of the degree programs aimed at the development of leadership among mid-career professionals. ${ }^{11}$ These programs are offered by a single school or department, or with alliances between a school of public health and other schools such as schools of business.

Second, a partnership between public health agencies and academia forms a certain program focused on public health leadership. In the US, the CDC/University of California Public Health Leadership Institute was initiated in 1991, funded by the CDC. In 2000, this was taken over by the University of North Carolina at Chapel Hill School of Global Public Health. Through the completion of the institute program, participants could enhance collaborative leadership and build knowledge and problem-solving networks among themselves. ${ }^{12}$ In 1998, the UK National Public Health leadership program, which originally launched as part of the Chief Medical Officer's project, was created for the purpose of enforcing public health functions in the National Health Service (NHS), designed for all people engaged in the public health agenda. ${ }^{13}$ In this program, participants learn through four elements (three residential modules of between two and four days, a final one-day session) for nine months. ${ }^{14}$ The first focuses on the development of understanding leadership skills. This module helps participants to have self-awareness and confidence regarding their leadership skills by using materials such as Myers Briggs Type Indicator (MBTI), other personality and leadership coding instruments and so on. In the second module, participants have the opportunity to improve their abilities to lead change by using learning materials as well, based on the needs assessed during the previous session. The third module gives the opportunity to test theories and skills obtained during the previous modules, working in teams of up to eight participants. The last is the 
presentation in which participants demonstrate how they put the skills and knowledge obtained during this program into practice. ${ }^{15}$ This program is nationally available. ${ }^{16}$

\section{Public health leadership education in Canada}

In response to a report by the Public Health Agency of Canada, which suggests strengthening the Canadian public health system with schools of public health, a number of schools of public health have been introduced in the past few years including the University of Alberta, the University of British Columbia, the University of Saskatchewan, and the University of Toronto. ${ }^{17}$ Among these new schools of public health, the University of Alberta offers a master's degree focused on public health leadership. ${ }^{18,19}$ Although the students seeking this program mainly consist of physicians who participate in the community medicine residency program or the occupational medicine residency program, the students attending the classes of public health leadership come from a variety of backgrounds, such as nurses, health administrators, and so on. The University of British Columbia School of Population and Public Health provides a course on public health leadership which is one of the commonly required courses to obtain an $\mathrm{MPH}$ degree. ${ }^{20}$ In addition to schools of public health educational programs, the University of Regina Centre for Continuing Education established the Saskatchewan Institute of Health Leadership which is financially supported by the government of Saskatchewan in partnership with the College of Physicians and Surgeons of Saskatchewan, the Saskatchewan College of Pharmacists, the Saskatchewan Registered Nurses' Association, and the Saskatchewan Society of Physicians Executives. ${ }^{21}$ This program is aimed at all levels within the healthcare system. The six-month certificate program offered by the Saskatchewan Institute of Health Leadership includes a week-long retreat in which lectures, workshops and group projects take place.

\section{Principles of education in public health leadership}

A number of training programs develop the skills and knowledge of public health leadership throughout the world. However, the competency based curricula are not well matched to the needs of students, especially in the areas of health policy, management, and leadership programs. ${ }^{22}$ Developing the curricula for degree programs is a challenging task because the public health workforce is not only diverse, but also ill-defined so far. In particular, the need to focus on competency development makes curriculum and program design much more challenging. All these programs have important implications for the factors impacting the effectiveness of public health leadership education. First, academia and public health agencies should create partnerships. It is clear, but must be kept in mind, that leaders are never developed only in the academic arena. People become leaders through their efforts, by taking correct steps in the real world. Academia assists them in this process. The teaching methods are under development and should be evaluated in the future in terms of their outcomes. Second, programs must encourage life-long learning. Leaders are life-long learners. $^{23,24}$ While public health professionals must make efforts to become life-long learners, academia and the public health practice sector should provide sustained training opportunities in order to help them by responding to their career stages. Third, programs must pay attention to the needs of individuals and communities. Whether the schools can accept a variety of students ranging from entry level to senior level depends on the funding and staff. Leadership education should be offered not only to the entry-level students to prepare for their future education, but also to senior level people who need to develop leadership skills immediately. In the US, the leadership training for health professions students is being developed. ${ }^{25}$ Fourth, flexibility should be developed. The curriculum should not be rigid but flexible so that the program can meet varied students' needs. To make this system effective, the program coordinator must discuss career goals with all students and guide them on which courses are suitable to achieve their goals. Last, programs must develop effective distance learning capabilities. Since internet technology has advanced, the distance learning format has become popular as a teaching approach all over the world. This gives those who have difficulties getting to a school appropriate access to learning opportunities and experience. This would serve to meet a variety of international needs, such as providing public health leadership training opportunities in countries where it would not otherwise be available and so permitting healthcare professionals to pursue their training part-time while still working full-time. This would reduce scarce manpower levels during their public health training and encourage health professionals to remain in their home countries rather than leaving for their education and then potentially not returning. These same phenomena would also pertain to underserved regions in North America.

\section{Conclusion}

Some countries have challenged this problem of developing their future public health leaders and are making progress. 
In Canada, this is beginning to happen in very positive ways and the emerging schools of public health can play an important role in the development of future public health leaders, especially when partnerships are developed with provincial and federal public health agencies.

\section{Disclosures}

The authors report no conflicts of interest in this work.

\section{References}

1. Roemer MI. Higher education for public health leadership. Int $J$ Health Serv. 1993;23(2):387-400.

2. Institute of Medicine. Who will keep the public healthy? Educating public health professionals for the 21st century. Washington, DC: National Academy Press; 2003.

3. Clark NM, Weist E. Mastering the new public health. Am J Public Health. 2000;90(8):1208-1211.

4. Council on Linkages Between Academia and Public Health Practice. http://www.phf.org/link/corecompetencies.htm\#view. Accessed May 5, 2009.

5. Institute of Medicine. The future of the public's health in the $21 \mathrm{st}$ century. Washington, DC: National Academy Press; 2002.

6. Association of Schools of Public Health. Master's Degree in Public Health Core Competency Development Project. Washington, DC: Association of Schools of Public Health; August 2006. http:// www.asph.org/userfiles/version2.3.pdf. Accessed May 7, 2009.

7. Public Health Agency of Canada. Core competencies for public health in Canada. Ottawa, ON: Public Health Agency of Canada; Sep 2007. http://www.phac-aspc.gc.ca/ccph-cesp/pdfs/cc-manual-eng090407.pdf. Accessed May 2, 2009.

8. Public Health Foundation. Report on healthy people 2010 objective 23-9 for midcourse review. Washington, DC. Public Health Foundation; Jul 2006. http://www.phf.org/reports/HP2010-23-9-midcourse. pdf. Accessed May 7, 2009.

9. Wright K, Rowitz L, Merkle A, et al. Competency development in public health leadership. Am J Public Health. 2000;90(8):1202-1207.

10. Institute of Medicine. The future of public health. Washington, DC: National Academy Press; 1988.

11. Halverson PK, Mays GP, Kaluzny AD, House RM. Developing leaders in public health: the role of executive training program. J Health Adm Educ. 1997;15:87-100.
12. Umble K, Steffen D, Porter J, et al. The National Public Health Leadership Institute: evaluation of a team-based approach to developing collaborative public health leaders. Am J Public Health. 2005;95(4):641-644.

13. Dalziel M. Leadership for health. How can we ensure that the values and principles of public health become central to health and social policy? J Epidemiol Community Health. 2000;54:703-704.

14. Imperial College London Faculty of Medicine. Leading for health: The National Public Health Leadership Programme 2008. http:// www 1.imperial.ac.uk/resources/88DBE5B4-E794-448F-AAC3A04C69BE2959/. Accessed May 17, 2009.

15. Chief Medical Officer. Report of the Chief Medical Officer's project to strengthen the public health function in England. London: Department of Health; March 28, 2001. http://www.dh.gov.uk/prod_consum_dh/ groups/dh_digitalassets/@dh/@en/documents/digitalasset/dh_ 4062359.pdf. Accessed May 20, 2009.

16. South West Public Health Training and Education. South West Regional Public Health Workforce Strategy 2008-2013. http://www. swph-education.org.uk/docs/wkfce_dev_strat_08.doc. Accessed June 18, 2009.

17. Moloughney BW. Schools of public health and the strengthening of public health systems in Canada - a discussion paper 2006. Public Health Agency of Canada; November 14, 2006. http://www.phac-aspc. gc.ca/php-psp/pdf/schools_of_public_health_discussion_paper_e.pdf. Accessed April 24, 2009.

18. Zakariasen K, Victoroff KZ, Karegyeya G. Developing a public health leadership graduate program responsive to a global perspective. Leadersh Health Serv. 2008;21(4):267-277.

19. Zakariasen K. Public health leadership: building a graduate program and a culture. Int J Learn. 2009;16(9):375-386.

20. University of British Columbia School of Population and Public Health. http://www.spph.ubc.ca/. Accessed May 24, 2009.

21. Saskatchewan Institute of Health Leadership. http://www.uregina. $\mathrm{ca} / \mathrm{cce} /$ business/SIHL/index.html. Accessed May 26, 2009.

22. Petrakova A, Sadana R. Problems and progress in public health education. Bull World Health Organ. 2007;85(12):963-965.

23. Kotter JP. Leading change. Boston, MA: Harvard Business School Press; 1996.

24. Kouses JM, Posner BZ. The leadership challenge. 3rd ed. San Francisco, CA: John Wiley \& Sons Inc; 2003.

25. Victoroff KZ, Schneider K, Perry C. Tomorrow's leaders, starting today: a pilot leadership development program for dental students. $J$ Dent Educ. 2009;73(3):311-318.
Journal of Healthcare Leadership

\section{Publish your work in this journal}

The Journal of Healthcare Leadership is an international, peer-reviewed, open access journal focusing on leadership for the health profession. The journal is committed to the rapid publication of research focusing on but not limited to: Healthcare policy and law; Theoretical and practical aspects healthcare delivery; Interactions between healthcare and society and evidence-based practices;

\section{Dovepress}

Interdisciplinary decision-making; Philosophical and ethical issues; Hazard management; Research and opinion for health leadership; Leadership assessment. The manuscript management system is completely online and includes a very quick and fair peer-review system. Visit http://www.dovepress.com/ testimonials.php to read real quotes from published authors. 